are also unsatisfactory for much research: historians may not know what records they need on a subject. The researcher accordingly needs comprehensive access to records, and cannot select specific documents for an FOIA request in advance ("NCC Briefing Sheet-December 8. 1988').

8. "Archives II" will be located on a 37-acre plot on the edge of a golf course. The architects are Hellmuth, Obata \& Kassabaum; the engineers are Ellerbe Becket. 1988 estimates for the cost of Archives II came to $\$ 206$ million.

9. "Remarks of Don W. Wilson, Archivist of the United States to the Staff of the National Archives March 31, 1988, Third Anniversary of Independence": "Walter Rundell Lecture" given by Don W. Wilson, Archivist of the United States, April 27, 1989.

10. My experience did not involve electronic records, but with the advent of electronic storage and retrieval systems, NARA and the Office of Management and Budget are aware of the problems attendant with such new technology. Indeed, in his address of March 31, 1988, U.S. Archivist Wilson listed computational concerns and machine readable records as his third chief concern. An Electronic Records Conference was convened and submitted recommendations to the President's Council on Management Improvement.

II. "Talking Points for Initial Efforts Toward Strengthening Declassification Policy," June 13, 1989. National Coordinating Committee.

12. Don W. Wilson, Walter Rundell Lecture, April 27, 1989. The NCC estimates that about one-third of the records are insufficiently described. "NCC Briefing Sheet-March 16, 1989."

13. "Remarks of Don W. Wilson," March $31,1989$.

14. "NCC Briefing Sheet-March 16, 1989," National Coordinating Committee.

15. "NCC Briefing Sheet-March 16, 1989," National Coordinating Committee. The American system does have its advantages. NARA allows researchers up to 21 boxes of records at one point of time and are open from 8:45 to 10:00 PM. Copies may be done by the re-

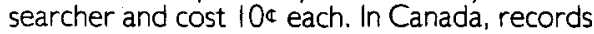
cost 20c, and have to be copied by staff, thus causing a week to ten-day wait for small orders, and a four- to six-week delay for larger orders. In Great Britain, records cost about 60٪ per page to reproduce; building hours are only 9:30 to 5:00 PM. Monday through Friday. On the other hand, the finding aids are computerized and the records are quickly available.

16. The pertinent Congressional committees are the House and Senate Appropriations Subcommittees on Treasury, Postal Service and General Government.
17. "Developing a Premier National Institution: A Report From the User Community to the National Archives, " by Page Putnam Miller, Director of the National Coordinating Committee for the Promotion of History. (Single copies of the report are available free by writing: Page Putnam Miller, NCC, 400 A St., S.E., Washington, D.C. 20003. Additional copies or bulk orders are $55 ₫$ per copy.)

To their credit, officials at the Archives have acknowledged the value of Dr. Miller's frank and frequently critical assessment of the operation and administration of the National Archives. The National Coordinating Committee is a consortium of over fifty historical, archival, political, library, and genealogical organizations (including the APSA).

18. "Developing a Premier Research Institution," pp. 5, 36.

19. "Remarks of Don W. Wilson," March 31, 1988."

20. Don W. Wilson, Walter Rundell Lecture, April 27, 1989; National Archives and Record Administration 1988, Annual Report, p. 3.

\section{Continuities in Political Research: Evidence from the APSR Since the 1960s*}

\author{
Samuel C. Patterson \\ Jessica R. Adolino \\ Kevin T. McGuire \\ Ohio State University
}

Since the American Political Science Review began publication in November 1906, its managing editor has reported annually to the council of the Association. These annual reports provide a valuable basis for understanding and recounting the development of the Review as a scholarly and scientific journal (see Patterson, Ripley, and Trish 1988). It is helpful to assess the performance of the Review in any one year by conducting both diachronic and comparative analyses of the ways in which the journal reflects, and perhaps influences, the etiology of political research.

In this analysis, we combine an evaluation of the performance of the APSR during 
Figure I. Number of Papers Submitted to the American Political Science Review, 1962-89

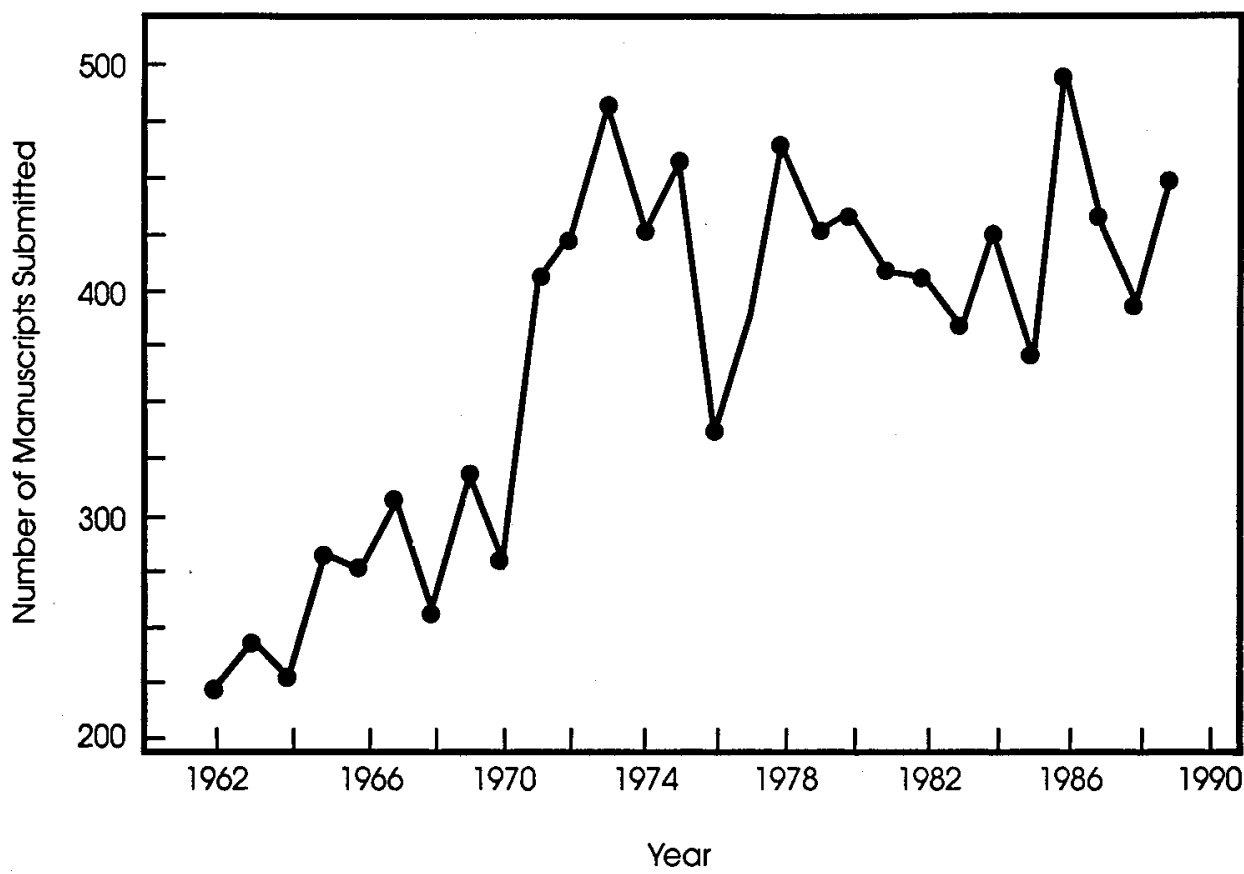

1988-89 with an assessment of the extent of continuity in manuscript submissions and acceptances since the 1960s, and a comparison of salient features of scholarly work published in the Review with those features of four other major political science journals (the American Journal of Political Science, the journal of Politics, Comparative Politics, and the International Studies Quarterly). The contrasts and continuities revealed by our data for the APSR and other journals over time puts the state of the discipline, as it is reflected in the journals, into perspective.

The Relentless Submission of Manuscripts

A scholarly journal's substantive content is very largely predetermined by the material scholars submit to its editor, Journals like the Review, the official organ of an association of scholars, come to have a life of their own. The editor of the day may make marginal improvements and changes (or do damage, in the worst case), but the fundamental shape and form of scholarly journals is very largely independent of the particular editor or editors of the moment. So, there is a basic sense in which the APSR is today what it has been for several decades.

In the late 1960s, political science began

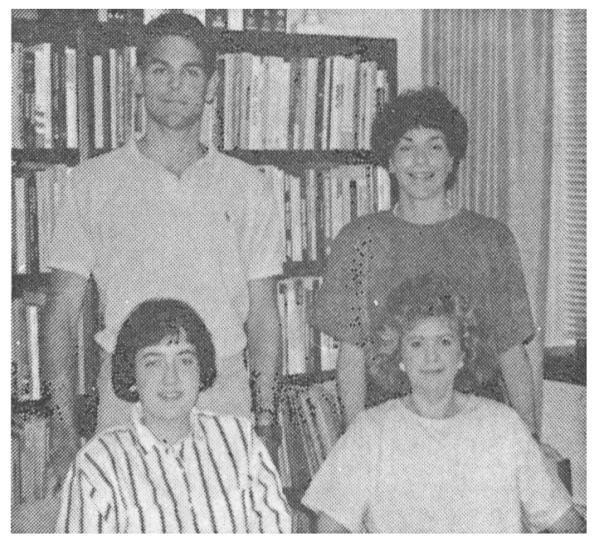

APSR interns, 1988-89 (standing) I. to r., Kevin McGuire and Jessica Adolino; APSR interns, 1989-90 (seated) I. to r., Shannon Smithey and Mary Ann Kasofsky. 


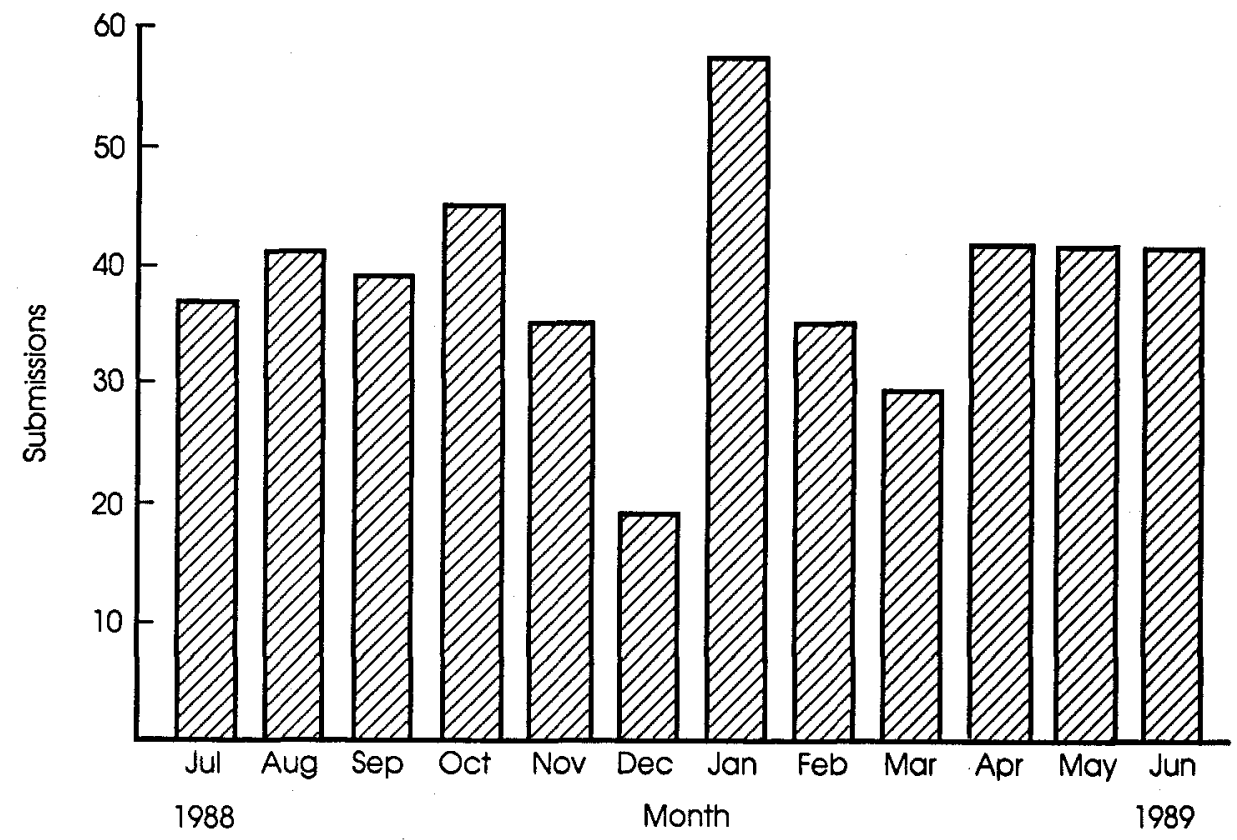

to grow as a profession. The increased number of practitioners eventually was reflected both in the proliferation of journals and in the growth of the submission rate for any one journal. But the submission of papers to the Review did not reflect this professional enlargement very dramatically until the 1970s (see Figure 1). In the 1960 s managing editors were, on average, sent about 270 manuscripts a year, not many more than the average of 260 manuscripts a year received by APSR editors in the 1950s. Nevertheless, as Figure I shows, some increase in the manuscript submission rate transpired in the 1960s.

The 1970s ushered in a new regime; managing editors began to get manuscripts in the range of $400-500$ a year. This growth in the submission rate reflected the more than doubling of the number of doctorates awarded in political science in the United States in the 1970s compared to the 1960s (Lynn 1983, 107). For the 1970s, the submission rate peaked at 484 manuscripts in 1973; for the 1980s, it peaked at the higher rate of 491 manuscripts in 1986. Secular fluctuations in the manuscript submission rate are not easy to explain year by year. One wonders what precipitated the plunge to only 340 submissions in 1976 , or to only 371 manuscripts in 1985. Without being able to offer a satisfactory accounting for submission trends, the managing editor of the day is, notwithstanding, at the mercy of yearly changes in the number of manuscripts offered for publication.

For 1988-89, the APSR experienced a rather dramatic increase in the submission of manuscripts. From the end of June 1988 to July 1989 the Review received 447 submissions, exceeding the figure for the previous year by $14 \%$. We received manuscripts at an average rate of 37 per month during this period, significantly surpassing the comparable 1987-88 figure. Figure 2 documents the month-to-month perturbations in submission rates for 1988-89, which we attribute to the vagaries of the academic schedule, the periodicity of national and regional political science conven- 
Table I. APSR Manuscript Submissions by Substantive Field, 1984-89

\begin{tabular}{lccccccc}
\hline & $1984-85$ & $1985-86$ & $1986-87$ & $1987-88$ & \multicolumn{2}{c}{$1988-89$} \\
\cline { 7 - 8 } Field & $\%$ & $\%$ & $\%$ & $\%$ & & \multicolumn{1}{c}{$\%$} & $\mathrm{~N}$ \\
\hline American politics & 23.1 & 31.0 & 33.5 & 32.5 & 35.1 & 157 \\
Comparative politics & 12.8 & 14.1 & 11.5 & 18.2 & 17.0 & 76 \\
International relations & 7.2 & 8.6 & 10.8 & 9.5 & 12.8 & 57 \\
Normative theory & 17.5 & 22.6 & 23.0 & 16.6 & 19.2 & 86 \\
Methodology & 8.8 & 2.2 & 2.5 & 5.9 & 1.6 & 7 \\
Public policy and administration & 7.2 & 9.4 & 10.7 & 7.2 & 5.4 & 24 \\
Formal theory & 23.4 & 12.1 & 8.0 & 10.2 & 8.9 & 40 \\
$\quad$ Total & 100.0 & 100.0 & 100.0 & 100.1 & 100.0 & 447 \\
\hline
\end{tabular}

tions, equinoctial regularities, Santa Claus, and the randomly distributed inspirations of authors.

As in previous years, first-time, fulllength manuscripts were the most common form of submission in 1988-89, constituting $91 \%$ (407) of the manuscripts received by the Review. This figure represents a $27 \%$ increase over the article submission rate for 1987-88. Authors continue to take advantage of the opportunity to revise and resubmit manuscripts for a second consideration by the Review; in 1988-89, 52 revisions were received, falling just short of the 54 revisions submitted in 1987-88.

We experienced a significant increase in the number of manuscripts submitted in research note and controversy formats in 1988-89. The APSR received 24 research notes and 16 controversies from the end of June 1988 to July 1989. The number of research notes submitted is over double the year-long total of 10 for 1987-88, and submitted controversies are twice the previous year's total of 7 . These latter figures may reflect our efforts to encourage authors to adapt full-length manuscripts to take advantage of these features of the Review, as well as an indication of the enthusiasm of our readers for these relatively new aspects of the journal.

The breakdown of submissions by substantive field for the current year and the past four years is shown in Table 1. Only very minor changes have transpired in submission levels across all fields relative to the previous year. Submissions in American politics continue to be high compared to the other subfields and are at their highest level in four years, accounting for over a third of all submissions. International relations and theory manuscripts received are at slightly higher levels than in the previous year, with the former achieving a new high. A significant increase in theory papers submitted rank that subfield second in terms of submissions; taken together with comparative politics, the two fields also account for over a third of submitted manuscripts. Comparative politics, which showed a dramatic increase in submissions in 1987-88, experienced only a slight decline. Of the remaining fields, methodology experienced the greatest decline, while formal theory remained relatively constant and public policy continued the previous years' downward trend.

\section{How the Subfields Fare in the General journals}

It is instructive to compare the kinds of political science published in various scholarly journals, and to assay changes over the years. We coded the articles published in the APSR and four other journals for five years in the 1960s and five years in the 1980 s in order to see how the Review had changed over the decades and how it compares with other journals. We chose to analyze the American journal of Political Science and the fournal of Politics because they are major general journals sponsored by associations. We examiried Comporative Politics and the International Studies 
Figure 3. Field Distribution of Articles in the APSR, AJPS, and JOP in the 1960s and the 1980s

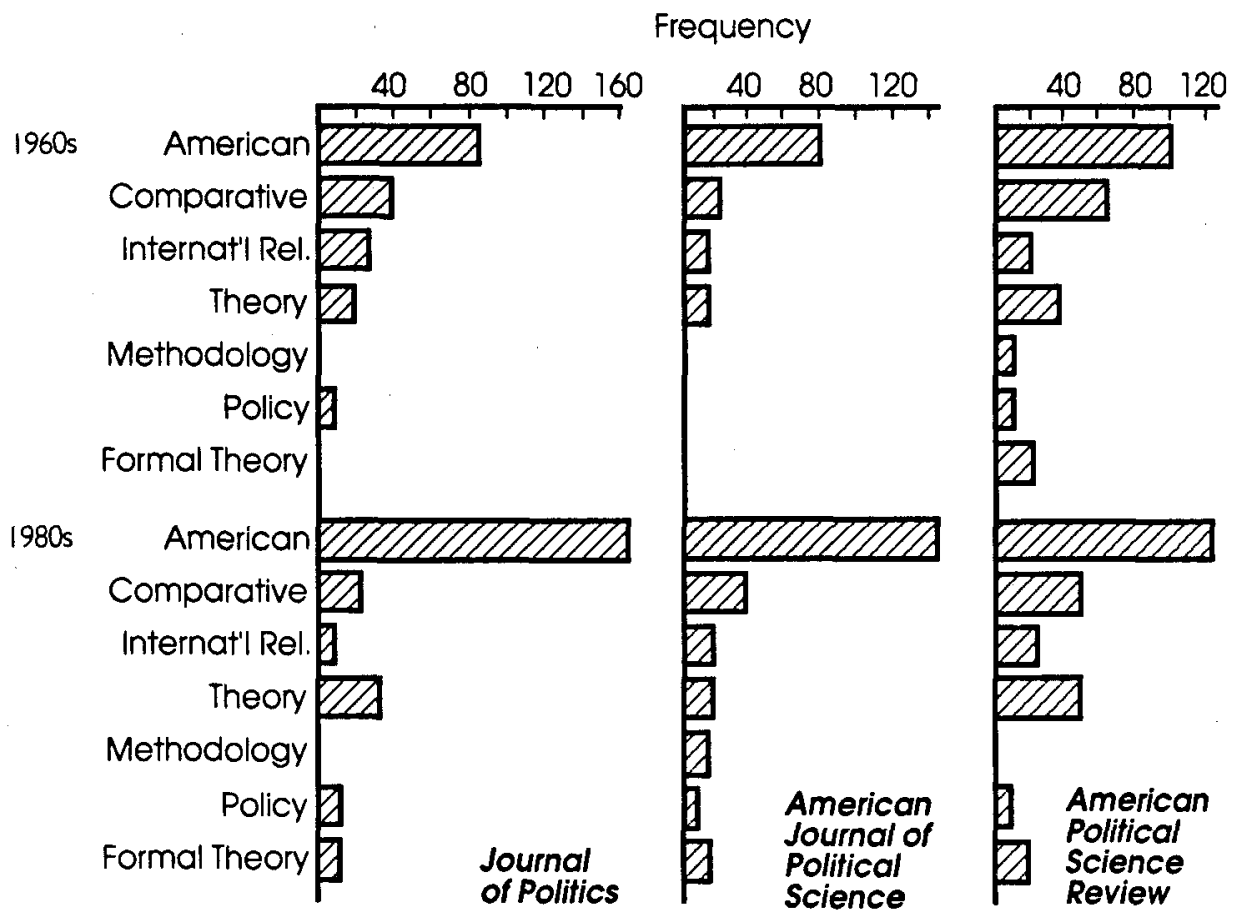

Quarterly because they are principal journals in the comparative and international fields. We did not attempt to investigate journal publication in other fields (e.g., political theory) because of constraints of time and difficulties of comparability.

The histograms shown in Figure 3 allow comparison of the Review with the other two general journals in terms of the field categories previously discussed (see Table 1). It is perhaps no surprise that the APSR carries fewer articles about American politics and more in the comparative field than either the AJPS or the JOP, or that there is somewhat more work in formal theory in the AJPS than in the Review or the JOP. What may be slightly startling is that the Review has, in the 1980s, published considerably more normative theory and international politics work than either of the other general journals, with the major ex- ception of the "workshop". articles published for a number of years in the A.JPS.

Given the shape of submissions by field, the Review seems to have maintained a satisfactory balance among subfields. Research on American politics provides more articles now than it did in the 1960s, but the Review is not dominated by American politics research in the way the AJPS and the JOP are; in these two journals, about two-thirds of the articles have drawn upon U.S. material. Clearly, data about U.S. political processes are readily available and there are many practitioners of research on American politics. It may indeed be an "overtilled field" (Arnold 1982).

The effort to recover contributions from the international relations field for the Review have paid some dividends (at the same time, the number of articles on international politics published in the ISQ 
more than doubled between the 1960s and the 1980s). The work published in the ISQ is mainly "international" and partly comparative in nature; as is to be expected, Comparative Politics publishes primarily "comparative" work. But the general journals remain heavily devoted to American research. As John C. Wahlke demonstrated for the 1970s, the Review continues, more than we would prefer, to exhibit "lack of generality, top-heavy emphasis on American politics, and insufficient breadth ..." (Wahlke 1979, 13). But the Review does suffer less from these frailties than do the other leading general journals.

\section{Methodology \& Data in the Journals}

Our interest in comparing the methodological and data characteristics of what we have been publishing in the Review with the contents of other journals led us to analyze articles published in the journals shown in Tables 2 and 3. In coding the content of journal articles, we focused upon the primary method and data. Where more than one coding category applied to an article, we asked: What is the primary method? Is this method central to the argument? Where did the bulk of the data come from? Which data does the author rely upon most heavily? Accordingly, we were quite successful in classifying work into one coding category or another.

First, we classified journal articles on the basis of their "methodological approach." Some we classified as being mainly philosophical, relying on normative or analytical theory; some invoked straightforward statistical inference; some rested on qualitative analysis, for example, case studies and policy analyses; and some developed formal, positive theory. Table 2 displays the distributions of journal articles in these methodological types.

From the 1960s to the 1980s, work published in the Review came increasingly to entail statistical inference and formal theory, and relied less on qualitative analysis. The other journals reflect their special character. The AJPS has been heavily statistical for a long time; the JOP and the ISQ seem to have taken a strong statistical turn in the 1980s; and Comparative Politics appears to have turned toward qualitative, case study analyses. The development of positive theory was firmly reflected in the Review and in the 15Q. less dramatically in the AJPS, and more tepidly in the other two journals.

We also classified journal articles on the basis of the type of data analyzed. Table 3 shows this analysis for the 1960s and the 1980s. In some studies, the data were gathered by the investigator who, for instance, undertook elite interviews, engaged in participation observation, or conducted special surveys. In other research, the data come from survey organizations like the Michigan Survey Research Center. Then, there are studies relying on documentary sources such as the census, election returns, court opinions, or roll-call records. Yet another category of research derives from secondary data-relying on published work or observations collected by others. Finally, some articles contain little or no data or observations; especially in the 1980s these were often public choice or other formal analyses.

In the general journals-the APSR, the AJPS, and the JOP-inquiry shifted most strikingly toward the use of survey data generated by polling organizations (the NES, the Gallup Poll, etc.). For the Review, about $9 \%$ of the 1960 s articles derived from such surveys, compared to nearly one quarter in the 1980s. In these general journals, data gathered by investigators from elite interviews or participant observation declined in use, although less so in the Review than in the AIPS or JOP; in contrast, data of this kind became more prevalent in Comparative Politics and the 15Q. Use of so-called documentary sourcesfor example, aggregate election data or roll-call votes-generally held steady or declined except for the JOP, where a substantial increase is evident. In all the journals, the proportion of articles not relying on data declined.

That our own research on journal content should demonstrate a modest growth over the last two decades in the use of statistical methodology and formal, analytic theory comes as no surprise. For the Review, Somit and Tanenhaus documented the rapid acceleration in the use of quanti- 


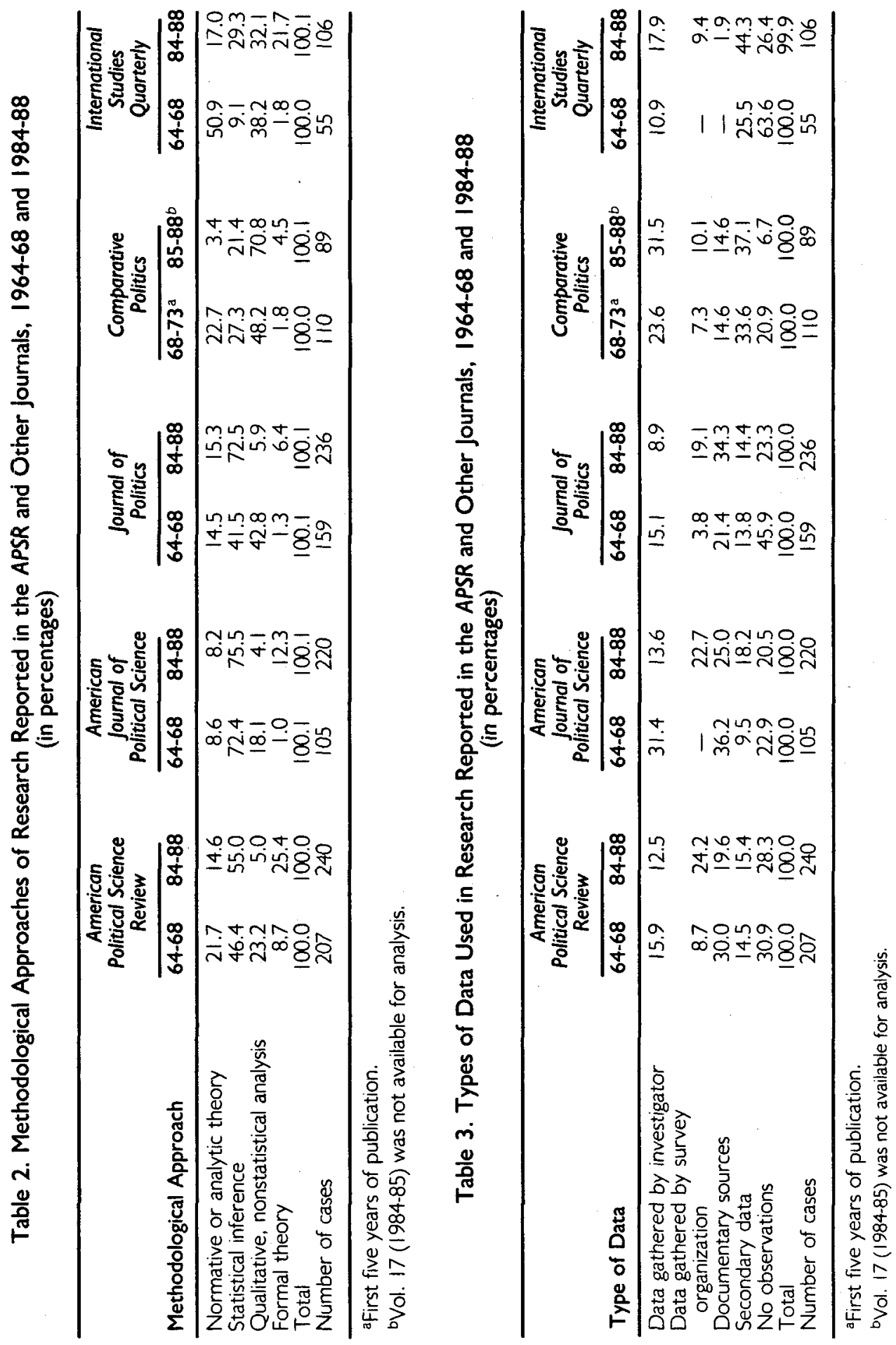


tative techniques in the years before our data were gathered. They found that "low level" and "more powerful" quantitative methods together characterized only about $12 \%$ of the APSR articles of the 1940 s, but this proportion grew to $16 \%$ in the 1950 s and $40 \%$ in the early 1960 s. Formal theory was nonexistent in the 1940s, but this kind of work evidenced some gains in the 1950s and 1960s, and came to constitute about a fourth of all APSR articles in the 1980s (see Table 2; Somit and Tanenhaus 1967, 192).

In an unpublished analysis of the Review, Heinz Eulau demonstrated the dramatic thirty-year shift since the 1950s toward individual-level, interview data in political research, and toward analytical theory, modeling, statistical simulation, and game theory. On 2 March 1988, he presented the results of his study of the Review in an APSR colloquium lecture at Ohio State University on "Environment and Context in the Study of Politics." He reported that the use of individual-level data jumped from about $9 \%$ of the Review's content in 1952-56 to nearly $28 \%$ in 1983-88; analytic theory and modeling work mushroomed from $3 \%$ in the 1950 s to $22 \%$ in the 1980 s (Eulau's proportions for the 1980s are somewhat different from ours mainly because he used a rather different approach.)

University of Wisconsin economist Theodore Morgan compared the nature and use of data in articles published in economics, political science, sociology, chemistry, and physics journals from 1982-86 (Morgan 1987, 9). His analysis showed that $42 \%$ of the articles in the American Economic Review developed mathematical models without any data, compared to $18 \%$ in the APSR, less than $1 \%$ in the American Sociological Review, zero in the Journal of the American Chemicol Society, and about $12 \%$ in Physical Review.

Morgan found the remaining published research of economists to be preponderantly based on data published or generated by others, rather than being generated on their own initiative (comprising $39 \%$ of the AER articles). He classified $41 \%$ of the APSR articles and $51 \%$ of the ASR articles in this category. In contrast, the vast majority of published research in chemistry is based on experiments and simulations, and this is also the case of nearly half of the articles in the physics journal. Our investigation of the nature of research published in the Review and other political science journals produced results in general agreement with Morgan's findings. The bulk of political science research, it may be said, is based on data which have not been newly generated by the investigators. Roughly one-fifth of published political science research contains no systematic observations, although most of this work falls under the aegis of normative theory rather than residing in the bailiwick of mathematical modeling.

\section{Accepting the Exceptional Manuscripts for the Review}

Of course, editors of the Review do not determine in advance what proportion of papers accepted for publication should fall into particular methodological or data categories. Analyses of the contents of scholarly journals provide more a commentary on the development of disciplines than on the behavior of editors. Editors face the influx of manuscripts seriatim, and make publishing decisions on the merits of each submission. For 1988-89, the editorial processes of the APSR were conventional, and produced results very consistent with earlier years of the 1980s.

Final decisions were made on 430 manuscripts between the end of June 1988 and July 1989. The sum total of decisions and submissions overlap but do not completely correspond because some decisions were made on papers submitted prior to the end of June 1988 and because a number of papers (9I all told) had yet to reach the end of the manuscript review process. Of the decisions reached on this 1988-89 input of manuscripts, $13 \%$ (55) were accepted for publication, $10 \%$ (41) were "revise and resubmit," and 78\% (334) were rejected.

Manuscripts accepted for publication are shown by substantive field in Table 4 . These figures by and large represent the proportion of space in the Review ultimately occupied by each field. One notable 
Table 4. APSR Manuscripts Accepted for Publication by Field, 1984-89

\begin{tabular}{|c|c|c|c|c|c|c|}
\hline \multirow[b]{2}{*}{ Field } & \multirow{2}{*}{$\begin{array}{c}1984-85 \\
\%\end{array}$} & \multirow{2}{*}{$\begin{array}{c}1985-86 \\
\%\end{array}$} & \multirow{2}{*}{$\begin{array}{c}1986-87 \\
\%\end{array}$} & \multirow{2}{*}{$\begin{array}{c}1987-88 \\
\%\end{array}$} & \multicolumn{2}{|c|}{$1988-89$} \\
\hline & & & & & $\%$ & $\bar{N}$ \\
\hline $\begin{array}{l}\text { American politics } \\
\text { Comparative politics } \\
\text { International relations } \\
\text { Normative theory } \\
\text { Methodology } \\
\text { Public policy and administration } \\
\text { Formal theory }\end{array}$ & $\begin{array}{l}20.0 \\
10.0 \\
10.0 \\
17.0 \\
10.0 \\
10.0 \\
23.0\end{array}$ & $\begin{array}{r}35.3 \\
13.7 \\
11.8 \\
17.6 \\
0.0 \\
11.8 \\
9.8\end{array}$ & $\begin{array}{r}40.0 \\
14.0 \\
10.0 \\
20.0 \\
0.0 \\
4.0 \\
12.0\end{array}$ & $\begin{array}{r}37.3 \\
13.7 \\
5.9 \\
17.6 \\
3.9 \\
9.8 \\
11.8\end{array}$ & $\begin{array}{r}27.3 \\
20.0 \\
10.9 \\
18.2 \\
0.0 \\
9.1 \\
14.6\end{array}$ & $\begin{array}{r}15 \\
11 \\
6 \\
10 \\
0 \\
5 \\
8\end{array}$ \\
\hline Total & 100.0 & 100.0 & 100.0 & 100.0 & 100.1 & 55 \\
\hline
\end{tabular}

change in acceptances since 1987-88 is the increase in comparative politics acceptances, with a $6.3 \%$ change that ranks the field as second in acceptances. International relations acceptances evidenced a $5 \%$ gain in 1988-89, with the actual number of acceptances in this subfield doubling over the previous year. American politics acceptances decreased significantly in percentage terms in 1988-89, reaching a three year low and showing the most dramatic decline of all the subfields. Changes in the other subfields were much more modest, with formal theory achieving its highest level in three years, methodology falling back to the pattern of the 1985-87 period, and public policy and normative theory remaining relatively stable.

Distributions of acceptance rates across substantive fields are shown in Table 5.
These rates reflect the number of acceptances out of the total number of decisions in each area. At about 13\%, the 1988-89 overall rate is similar to the 1986-87 and 1987-88 rates. Except for "pure" methodology, which has reverted to the norm of no acceptances, the formal theory and public policy fields differ most significantly from the 1988-89 composite rate, with one-fifth of the decisions in public policy and one-sixth of those in formal theory being acceptances.

The significance of some small fluctuations from year to year is often not clear, and the explanation for variations among fields is obscure. But the main tendency in our monitoring of performance is that of continuity. Aside from a general increase in manuscript submissions, patterns of submission remain quite constant.

Table 5. APSR Acceptance Rates for Substantive Fields, 1986-89

\begin{tabular}{|c|c|c|c|}
\hline \multirow[b]{2}{*}{ Field } & \multicolumn{3}{|c|}{ Percent of Acceptances in Field for: ${ }^{a}$} \\
\hline & $1986-87$ & $1987-88$ & $1988-89$ \\
\hline $\begin{array}{l}\text { American politics } \\
\text { Comparative politics } \\
\text { International relations } \\
\text { Normative theory } \\
\text { Methodology } \\
\text { Public policy/administration } \\
\text { Formal theory } \\
\text { Overall }\end{array}$ & $\begin{array}{l}14.8(20)^{\mathrm{b}} \\
14.3(7) \\
11.0 \quad(5) \\
10.2(10) \\
0.0 \quad(0) \\
4.3(2) \\
17.6(6) \\
13.0(50)\end{array}$ & $\begin{array}{rr}14.6 & (19) \\
10.3 & (7) \\
7.5 & (3) \\
12.2 & (9) \\
9.5 & (2) \\
14.7 & (5) \\
17.6 & (6) \\
12.7 & (51)\end{array}$ & $\begin{aligned} 9.8 & (15) \\
15.9 & (11) \\
11.5 & (6) \\
13.0 & (10) \\
0.0 & (0) \\
20.0 & (5) \\
18.2 & (8) \\
12.3 & (55)\end{aligned}$ \\
\hline
\end{tabular}

a Rates are based on total decisions in each field: American politics, 153; comparative politics, 69; international relations, 52; normative theory, 77; methodology, 10; formal theory, 44; public policy and administration, 25.

bFrequencies in parentheses. 


\section{APSR Staff and Editorial Board}

The content of a scholarly journal is a robust function of the papers submitted to it, but a working editorial staff is needed to bring this work to fruition in quarterly issues of the magazine. The staff of the Review at Ohio State University includes Managing Editor Samuel C. Patterson, Associate Editor Jean P. Kelly, and Copy Editor Michael K. Lane. Currently, Sharon E. Heinrich serves as Editorial Assistant. For 1988-89, the APSR Interns were Jessica R. Adolino, whose field of specialization is comparative politics, and Kevin $T$. McGuire, a specialist in American judicial politics and constitutional law. The interns for 1989-90 are Shannon K. Smithey and Mary Ann Kasofsky. Book Review Editor Helen M. Ingram, whose offices are at the University of Arizona, assisted by Book Review Intern Penny Clark, copes with the remarkable influx of books coming to the Review for review.

A new editorial board is serving the APSR for Vols. 83-85. The current board members are as follows:

Gregory A. Caldeira, Ohio State University

Pamela J. Conover, University of

North Carolina

Matthew Holden, Jr., University of

Virginia

Robert Jervis, Columbia University

Malcolm E. Jewell, University of

Kentucky

Charles $\mathrm{O}$. Jones, University of

Wisconsin

Donald R. Kinder, University of

Michigan

Anthony King, University of Essex

Allan Kornberg, Duke University

Arend Lijphart, University of

California, San Diego lowa

Gerhard Loewenberg, University of

Tha

Thomas E. Mann, Brookings Institution

Robert H. Salisbury, Washington

University

Arlene W. Saxonhouse, University of

Michigan

Elaine B. Sharp, University of Kansas

Kenneth A. Shepsle, Harvard

University

\section{Randolph Siverson, University of}

California, Davis

Editorial board members serve a term of three years. Changing the membership of the board every three years permits a range of political scientists to have experience working closely with the Review, and also spreads the burden of work among busy scholars. We thank those who served on the editorial board from 1985-88.

\section{How is It Done?}

Working scholars concerned about getting their research and ideas into print, and many work-a-day readers of scholarly literature, sometimes think of manuscript submission and journal production activities as puzzling, mysterious, and perhaps even quite vexing. For this reason, editors frequently feel rightly compelled to describe the editorial review and publishing processes (see Zinnes 1985; Jones 1986; Giles, Patterson, and Mizell 1989; see also Laponce 1980).

Editing the Review is a multi-stage process. New manuscripts arrive at the rate of more than one a day. These undergo scrutiny by the Review staff, and then referral to peer reviewers (usually two or three). In this process, assiduous efforts are made to provide prompt and efficient service to authors who submit their work to the Review. There is no mystery in doing this properly, but it does require careful record-keeping, constant surveillance, and, above all, appropriate selection of referees. The vast majority of manuscripts submitted are not accepted for publication in the Review, but the "seminar by mail" provides an important part of the enterprise of scholarly achievement and development. Rejected authors, who get two or three cogent professional critiques of their work, often succeed in revising papers for publication in other journals. Frequently we see our handiwork in print elsewhere.

Publishing four issues of the Review each year is a daunting enterprise in itself. At any one time, the staff is working on each issue at its own stage in the production of the journal. First, an issue is in press or in print; this is the latest of the editorial 
Table 6. Time in the APSR Manuscript Review Process in Days, 1988-89

\begin{tabular}{lr}
\hline Step in the Review Process & $\begin{array}{c}\text { Mean Time } \\
\text { Required }\end{array}$ \\
\hline Time from receipt of manuscript to assignment & 12.2 days \\
Time from assignment to receipt of last referee report & 37.4 days \\
Time from receipt of last referee report to decision & 8.2 days \\
Total time from receipt of manuscript to decision & 52.2 days \\
\hline
\end{tabular}

staff's handiwork, which staff members and authors caress and point to with pride. Second, an issue is in galleys or page proofs, the product of craftsmanship and copyediting. Third, we are copyediting a manuscript of about 850 pages, a complex and diverse manuscript indeed-containing scholarly work ranging from econometric modeling to exegesis from Thucydides (sometimes in Greek)-and reviewing books from across the discipline. Fourth, we are accepting manuscripts for a forthcoming issue; this activity consumes our main interest in current manuscripts, and represents our hope for the future. This is the ordinary flow of the work of publishing the Review. When each new issue of the APSR arrives at the journal office, we all admire the work of a new set of authors published as handsomely as we can publish them.

\section{The Crucial Process of Reviewing the Manuscripts}

A common concern of many scholars submitting manuscripts to the Review is the length of time it takes for the review process to be completed. Table 6 shows the mean time for peer review and the other two major phases-referee assignment and final decision-of the review process.

The average manuscript spends about twelve working days at the Review offices, and about seven weeks in the hands of reviewers, for a total of ten weeks from receipt to decision. Figure 4 illustrates the distribution of submission turnaround time; the model submission takes about 9 weeks from receipt to editor's decision. The distribution shown in this figure indicates substantial variation in manuscript processing time; this fluctuation can be at- tributed to the perils of the peer review system (i.e., referee cancellations and delays), and lengthier in-house review times in the face of increased submissions and periods with above average levels of submissions.

Peer review of scholarly papers is vital to the journal enterprise. It should be a professional, timely, and effective process, and by-and-large it is so. Much of the time this process entails negative outcomesdecisions not to publish papers submitted. No scholar enjoys receiving a rejection letter from a journal editor. But this outcome is easier on the author, and professionally more justified, if the decision is rendered promptly, if the review process has been fair, and if the peer reviews provide the author with constructive criticism. In the real world, scholarly peer review is far from a perfect process. But on the whole it works pretty well (see Patterson et al. 1987, 1011-1016; Giles, Patterson and Mizell 1989). This is true largely because norms have developed within the discipline of political science that set professional standards for scholarly and scientific research, and provide intrinsic rewards for the effective performance of indispensable professional obligations.

\section{The Importance of Reviewing Books}

The Review maintains an extensive program of reviewing scholarly and scientific books in political science and related fields. It provides the principal resource in the political science discipline for book reviews, although the journal of Politics reviews a substantial number of books as well. Other general journals-notably the American Journal of Political Science and the 
Figure 4. Time Between APSR Manuscript Receipt and Editorial Decision, 1988-89

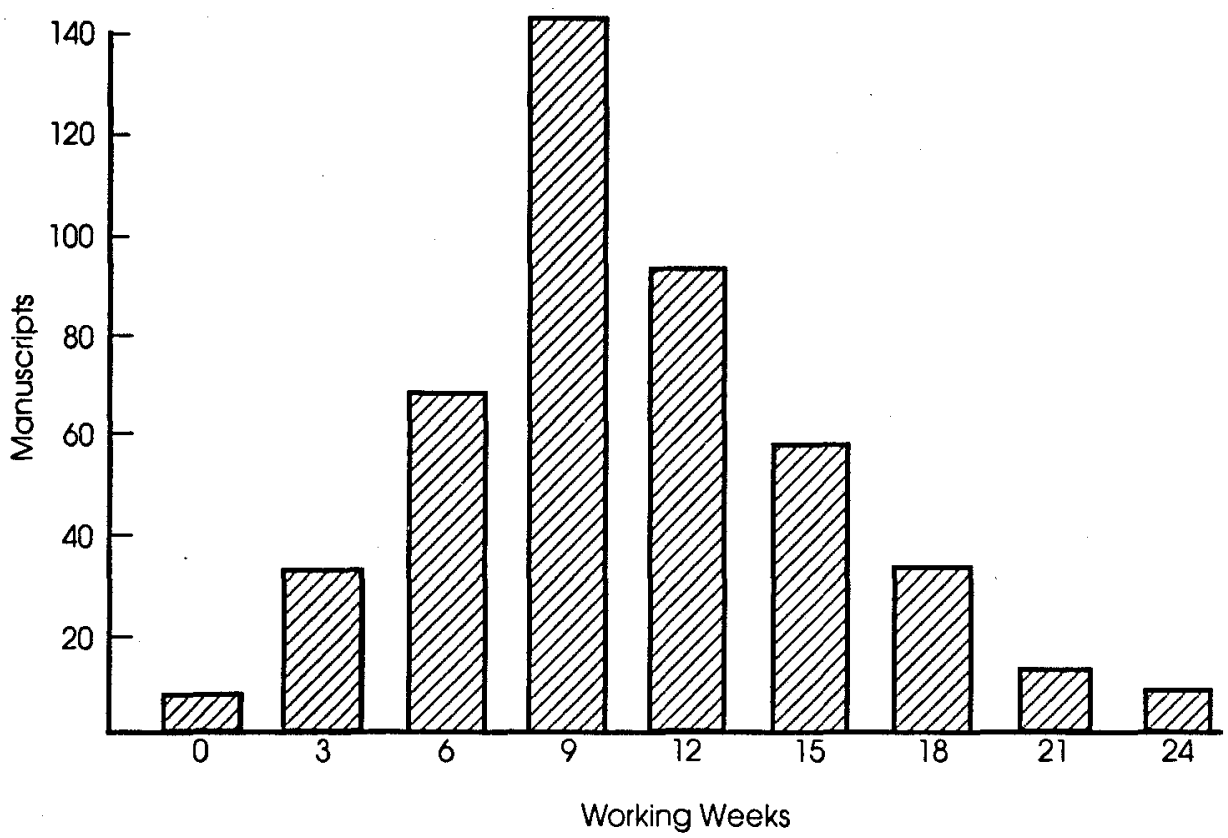

Western Political Quarterly-do not review books.

The avalanche of books sent to the APSR redounds upon Book Review Editor Helen M. Ingram and the staff at the University of Arizona. During 1988-89, 160 publishers mailed 1,700 books to the book review editor. From this mountain of books, 361 were chosen for review (99 were in American politics; 105 in comparative politics; 94 in international relations; and 63 in political theory).

Although the lion's share of book reviewing in political science is provided by the Review, the enterprise is quite widelyshared. The APSR book review files now contain more than 2,200 potential reviewers from over 300 institutions. Yet, the general willingness to review books is not evenly distributed across institutions. Research by the book review staff shows that only 42 percent of the potential reviewers at the top ten universities in the United States agreed to write reviews, compared to a 67 percent acceptance rate overall.

Today, the Review is reviewing more books and devoting more space to book reviews than it has in recent years. In 1989 the APSR carried reviews of 407 books, compared to only 327 in 1988 and 352 in 1987. The distribution of these books in terms of the major political science subfields is given in Table 7. The proportion of reviewed books in each of the subfield categories has been quite invariant over the 1980s. Each general subfield has been well-represented among book reviews published in the journal.

Finally . . .

We have reported both about the performance of the Review during 1988-89. and about the shape and form of the Review compared to other journals in the 1960 s and 1980s. We do the former fairly standardized kind of monitoring of performance in order to keep our own efforts up to par and to report our stewardship of the Review to our professional colleagues. We investigated methodological 
Table 7. Subfield Distribution of Books Reviewed in the APSR, 1985-89

\begin{tabular}{lccccc}
\hline & \multicolumn{5}{c}{ Percentage of Books Reviewed } \\
\cline { 2 - 6 } Field & 1985 & 1986 & 1987 & 1988 & 1989 \\
\hline Political theory & 21 & 18 & 17 & 19 & 18 \\
Political economy & 32 & 7 & 9 & 6 & $*$ \\
American politics & 28 & 27 & 28 & 31 \\
Comparative politics & 19 & 24 & 31 & 28 & 27 \\
International relations & 100 & 100 & 100 & 100 & 100 \\
Total & 100 & & & & \\
\hline
\end{tabular}

*Included in other subfields.

and data developments in the APSR and other journals over time because of our interest in the sociology of knowledge in political science, and our awareness of the obvious nexus between day-to-day practice in editing a journal and the systemic consequences.

The APSR staff enjoys the luxury of working with manuscripts of high quality, making possible the publication of a quarterly journal of exceptional merit. The fact that the Review continues to carry very excellent scholarly and scientific papers is a tribute to the collective enterprise-a mixture of the excellence of the research of social scientists who submit their work to the APSR, the conscientious service of our colleagues who serve as peer reviewers, the advice and counsel of the editorial board, the loyalty and skill of the APSR staff at Ohio State University, the diligence of those who compose and print the journal, and the support of the APSA Washington staff who assure that we all receive the Review once it is published.

\section{Note}

*This article constitutes the 1988-89 annual report of the managing editor of the American Political Science Review. Samuel C. Patterson is currently managing editor. Jessica $R$. Adolino and Kevin T. McGuire were APSR interns for 1988-89. We thank associate editor Jean P. Kelly for assistance.

\section{References}

Arnold, R. Douglas. 1982. "Overtilled and Undertilled Fields in American Politics."
Political Science Quarterly 97: 91-103.

Giles, Micheal W., David Patterson, and Francie Mizell. 1989. "Discretion in Editorial Decision-Making: The Case of the fournal of Politics." PS: Political Science \& Politics 22: 58-62.

Jones, Charles 0.1986. "On Being an Editor Twice." PS 19: 87-88.

Laponce, J. A. 1980. "Political Science: An import-Export Analysis of Journals and Footnotes." Political Studies 28: 401-19.

Lynn, Naomi B. 1983. "Self-Portrait: Profile of Political Scientists." In Political Science: The Stote of the Discipline, ed. Ada W. Finifter. Washington, DC: American Political Science Association.

Morgan, Theodore. 1987. "Academic Economics: A Pulse-Taking; Comparisons." Department of Economics, University of Wisconsin, Madison. Typescript.

Patterson, Samuel C., Brian D. Ripley, and Barbara Trish. 1988. "The Americon Political Science Review: A Retrospective of Last Year and the Last Eight Decades." PS: Political Science \& Politics 21: 908-25.

Patterson, Samuel C., Michael S. Bailey, Valerie 1. Martinez, and Susan C. Angel. 1987. "Report of the Managing Editor of the American Political Science Review, 1986-87." PS 20: 1006-16.

Somit, Albert and Joseph Tanenhaus. 1967. The Development of American Political Science: From Burgess to Behavioralism. Boston: Aliyn and Bacon.

Wahlke, John C. 1979. "Pre-Behavioralism in Political Science." American Political Science Review 73: 9-31.

Zinnes, Dina A. 1985. "Reflections of a Past Editor." PS 18: 607-12. 